\title{
Nova pandemia, velhas formas de prevenção: fabricação e doação de produtos saneantes domissanitários para famílias em situação de vulnerabilidade social
}

\section{RESUMO}

Adriano Lopes Romero adrianoromero@utfpr.edu.br Universidade Tecnológica Federal do Paraná

David Lucas Zegolan Marcondes davidlucasmarcondes@gmail.com Universidade Tecnológica Federal do Paraná

Isaac Felipe Machado isaacfelipe99@gmail.com Universidade Tecnológica Federal do Paraná

Maria Vitória de Oliveira Rodrigues

mvitoriadeoliveira1@gmail.com Universidade Tecnológica Federal do Paraná

Leila Isabel da Silva

leilaambientalmk25@hotmail.com Secretaria de Meio Ambiente do município de Quarto Centenário

Stenio Cristaldo Heck

stenioheck@gmail.com

Universidade Estadual de Maringá

Stephani Caroline Beneti

stephanibeneti@utfpr.edu.br

Universidade Tecnológica Federal

do Paraná

Rafaelle Bonzanini Romero

rbromero@utfpr.edu.br

Universidade Tecnológica Federal do Paraná
O uso de produtos saneantes domissanitários é uma das formas de prevenção da disseminação de agentes causadores de doenças, tal como o coronavírus que tem causado a pandemia COVID-19. De modo geral, as pandemias podem causar danos à saúde de toda a população, mas são particularmente prejudiciais aos membros de grupos sociais em situações mais vulneráveis. Nesse contexto, o grupo, formado por professores e estudantes da UTFPR - câmpus Campo Mourão, tem fabricado produtos saneantes domissanitários que são doados para famílias em situação de vulnerabilidade social dos municípios de Campo Mourão, Quarto Centenário, Rancho Alegre d'Oeste e Roncador. Entre os saneantes doados destacamos, devido a quantidade produzida/doada, os sabões em barra e líquido, que são fabricados a partir de óleos usados em fritura doados por moradores dos municípios mencionados. Até o momento foram doados cerca de 600 kits de sabão em barra e 2000 litros de sabão líquido, assim como folhetos informativos sobre a pandemia.

PALAVRAS-CHAVE: Extensão universitária. Agentes sanitizantes. Sabão. COVID-19. 


\section{INTRODUÇÃO}

Estamos vivenciando uma nova pandemia, que se originou a partir de um surto de pneumonia de etiologia desconhecida na cidade de Wuhan, na China, em dezembro de 2019. Um coronavírus foi identificado como agente causador e, posteriormente, foi denominado COVID-19 pela Organização Mundial da Saúde (OMS). O agente causador é semelhante ao da síndrome respiratória aguda grave (SARS) e da síndrome respiratória do Oriente Médio (MERS), o COVID-19 é causado por um coronavírus denominado SARS-CoV-2, que afeta o trato respiratório inferior e se manifesta como pneumonia em humanos (SOHRABI et al., 2020). Apesar dos esforços globais de contenção e quarentena, a incidência de COVID-19 continua a aumentar. Dados da OMS, acessível em https://www.who.int/emergencies/diseases/novel-coronavirus-2019/situationreports, do dia 14 de maio indicam que há 4.248 .389 casos confirmados em laboratório e mais de 294.046 mortes em todo o mundo.

Assim como ocorreu em outros momentos, discussões acerca de higienização como forma de prevenir a disseminação de agentes causadores de doenças têm sido realizadas com certa frequência. A higienização das mãos, por exemplo, é considerada uma das principais formas de combater a disseminação do vírus causador da COVID-19. Dentre os vários produtos disponíveis comercialmente, a Agência Nacional de Vigilância Sanitária (Anvisa) indica o uso de sabão ou de preparações alcoólicas - cuja concentração final seja entre 60 e $80 \%$ para preparações sob a forma líquida, e concentração final mínima de $70 \%$ no caso de preparações sob as formas gel, espuma e outras - para higienização das mãos (ANVISA, 2010).

Pensando no contexto apresentado, uma proposta de projeto foi submetida Implementação de uma planta piloto para fabricação e transferência de tecnologia relacionada à produtos saneantes domissanitários - ao edital ํo 06/2020 PROREC/PROPPG, que foi classificada e apoiada financeiramente pela Diretoria de Relações Empresariais e Comunitárias do câmpus Campo Mourão da UTFPR. Devido ao orçamento disponibilizado ser menor do que o solicitado na proposta, os esforços e recursos financeiros foram focados para a fabricação de produtos saneantes de menor custo, tais como o sabão em barra, sabão líquido e água sanitária que foram entregues, por meio de parceria, para os municípios de Campo Mourão, Quarto Centenário, Rancho Alegre d'Oeste e Roncador que realizam as doações para famílias em situação de vulnerabilidade social.

\section{ASPECTOS ACERCA DA HIGIENIZAÇÃO DAS MÃOS}

Do ponto de vista histórico, a lavagem das mãos com água e sabão é considerada uma medida de higiene pessoal há séculos, sendo incorporada em hábitos religiosos e culturais. No entanto, a relação entre a lavagem das mãos e a propagação de doenças foi estabelecida apenas dois séculos atrás. Em meados do século XIX, os estudos do médico húngaro Ignaz Philipp Semmelweis (1818 - 1865) e do médico norte-americano Oliver Wendell Holmes (1809 - 1894) estabeleceram que as doenças adquiridas em hospitais eram transmitidas pelas mãos dos profissionais de saúde.

O sabão, o mais antigo dos produtos utilizados para higienização das mãos, foi descoberto durante a pré-história de forma acidental e observação casual. As 
evidências de produção de diferentes tipos de sabão datam do terceiro milênio antes da Era Cristã. De modo geral, até o início do século XIX, o sabão era produzido a partir da lixiviação das cinzas. A química envolvida nesse processo foi publicada em 1813 pelo químico francês Michel Eugène Chevreul (1786 - 1889) que estudou a composição de gorduras e o processo de fabricação de sabão (WISNIAK, 2004).

Para entender o mecanismo virucida do sabão deve-se considerar a estrutura externa do vírus, que é constituída por proteínas e fosfolipídios, de caráter anfifílico, porção hidrofílica e uma porção hidrofóbica, pouco solúveis em água. Já o sabão possui compostos anfifílicos na sua composição, tal como a membrana viral, que são utilizados para dissolver gorduras, sendo geralmente denominados agentes tensoativos. Um exemplo típico é o estearato de sódio, componente comum nos sabões. Quando dissolvidos em água esses tensoativos formam micelas: agregados moleculares esféricos, onde as regiões hidrofóbicas ficam orientadas para o centro, protegidas do solvente aquoso, e as regiões hidrofílicas ficam para fora, expostas ao solvente. Essas micelas têm a capacidade de encapsular materiais hidrofóbicos (semelhante ao vírus) no seu interior, e assim, "solubilizá-los" em água (FERNADES; RAMOS, 2020).

\section{O PROJETO EM FOCO}

A matéria-prima principal para produção dos sabões - o óleo usado em fritura - foi obtido a partir de doações de moradores dos municípios parceiros, que foram conscientizados acerca do projeto por meio de textos informativos divulgados em redes sociais. Duas formulações, considerando a perspectiva custo-benefício, foram utilizadas:

- Fabricação de sabão em barra: Em um recipiente de plástico agitou-se por 30 minutos 5 litros de óleo utilizado em fritura filtrado e $200 \mathrm{~mL}$ de água sanitária. Na sequência adicionou-se $1 \mathrm{~kg}$ de soda cáustica $99 \%$ dissolvido em 5 litros de água. A mistura foi agitada mecanicamente (ou manualmente) até a obtenção de uma pasta de consistência uniforme. $\mathrm{Na}$ sequência, a pasta foi colocada em formas plásticas e mantidas em temperatura ambiente por $24 \mathrm{~h}$ para secar. Após esse período, o sabão foi cortado em barras e mantidos, separadamente, sob a bancada, por pelo menos cinco dias, para realizar o processo de cura.

- Fabricação de sabão líquido: Em um recipiente plástico agitou-se 5 litros de óleo utilizado em fritura filtrado e 1 litro de água sanitária por 30 minutos. Na sequência adicionou-se, com agitação constante, 3 litros de álcool etílico hidratado e $1 \mathrm{~kg}$ de soda cáustica 99\% dissolvida em 1,5 litros de água. A mistura foi agitada mecanicamente (ou manualmente) até a obtenção de uma pasta de consistência uniforme. Posteriormente, 7 litros de água quente foram utilizados para dissolver a pasta obtida. A essa mistura concentrada adicionou-se água até completar 100 litros de solução. Após $24 \mathrm{~h}$, obteve uma solução pastosa (cuja consistência é dependente da temperatura) que foi diluída até a obtenção de uma solução homogênea de consistência desejada.

As doações dos produtos fabricados foram realizadas - por intermédio dos municípios parceiros - para famílias em situação de vulnerabilidade social. Até o 
dia 14 de maio deste ano foram doados 600 kits de sabão em barra e 2000 litros de sabão líquido (Figura 1).

Figura 1 - Alguns lotes de produtos saneantes domissanitários doados.
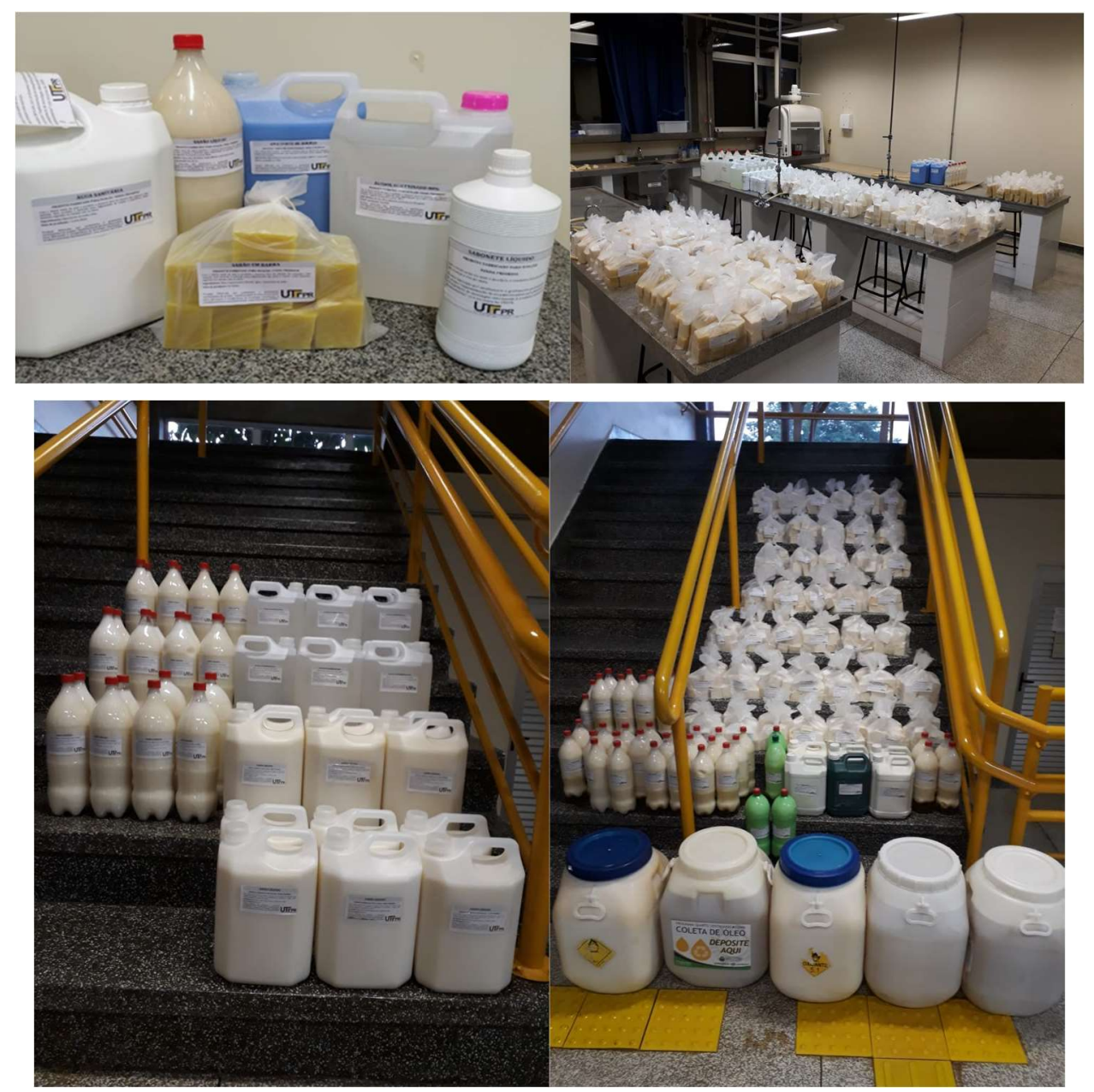

Fonte: Acervo dos autores.

Além dos produtos saneantes domissanitários, foram doados também folhetos informativos sobre a pandemia, formas de prevenção e de uso de saneantes (Figura 2). No folheto, por exemplo, é informado que agência Centers for Disease Control and Prevention (CDC) [Centros de Controle e Prevenção de Doenças], no contexto da limpeza e desinfecção doméstica, recomenda para a limpeza e desinfecção de superfícies o uso de soluções diluídas de alvejante doméstico, soluções alcoólicas com pelo menos $70 \%$ de álcool e desinfetantes domésticos. Segundo essa agência "[...] o alvejante doméstico não vencido será eficaz contra os coronavírus quando adequadamente diluído", que indica 4 colheres de chá de água sanitária por litro de água. Para a higienização das mãos, a CDC recomenda que os membros da família devem limpar as mãos com frequência, inclusive imediatamente após remover as luvas e após o contato com uma pessoa doente, lavando as mãos com água e sabão por 20 segundos. Se não houver água e sabão e as mãos não estiverem visivelmente sujas, um desinfetante 
para as mãos à base de álcool que contenha pelo menos $60 \%$ de álcool pode ser usado (CDC, 2002).

Figura 2 - Folheto informativo distribuído às famílias em situação de vulnerabilidade social de Campo Mourão.

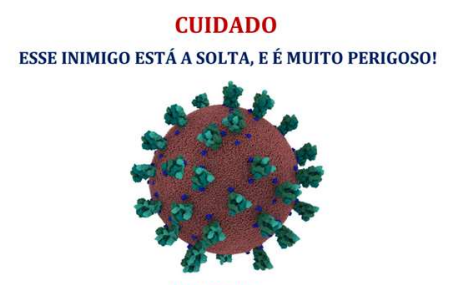

0 nome dele é CoviD-19, um vírus da família dos Coronavírus, que começou a contaminar as pessoas na China e hoje está presente em praticamente todos os paises do mundo, inclusive na nossa cidade. Esse virus pode causar uma infecção respiratoria, que pode variar desde una simples gripe até em risco.

As complicaçōes mais sérias desta infecção parecem surgir especialmente em pessoas idosas com idade superior a 60 anos, mas o virus pode afetar pessoas de todas as idades, sendo, por isso, muito importante ficar atento ao surgimento de sintomas que possam indicar a infeçao, especial

Esse inimigo invisível aos nossos olhos é transmitido por cuidados para evitar pegar a infecção e passá-la para outras pessoas, como cobrir a boca ao tossir ou espirrar, lavar as mãos regularmente e evitar tocar no rosto, principalmente na região dos olhos, nariz e boca.

$$
\sim 1 \sim
$$

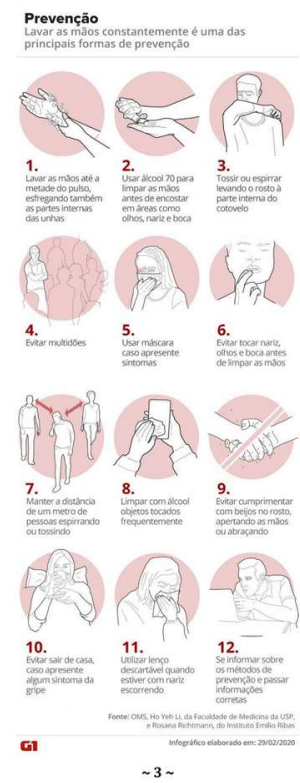

Ao tossir ou espirar pequenas gotículas com esse vírus são eliminadas para o ambiente, o que faz com que uma única pessoa possa disseminar esse vírus para várias outras pessoas. Muita pessoas podem estar infectadas com esse virus, mas não

Mesmo sendo tão pequeno, esse vírus é extremamente perigoso. Até $\mathbf{o}$ dia 13 de maio esse vírus infectou 4.088 .848 pessoas no mundo todo (o que equivale a aproximadamente 43 vezes a populaçăo de Campo Mourão) e matou 283.153 (o que equivale a aproximadamente 3 vezes a população de Campo

Quais os cuidados devemos ter com esse inimigo?

Uma das principais medidas de prevenção ao coronavírus indicada pela Organização Mundial da Saúde (OMS) é lavar as mão com água e sabão. 0 sabão, por ser uma substancia que quebra a

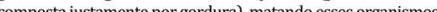

o Conselho Federal de Química (CFQ) explica que o uso de água e sabão e do álcool gel na higienizaçáo das mâos ajudam na prevenção ao contágio de doenças por serem antissepticos - agem detergentes de um modo geral, graças às suas propriedades químicas removem a maior parte da flora microbiana na superfície da pele explicou o CFQ.

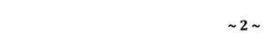

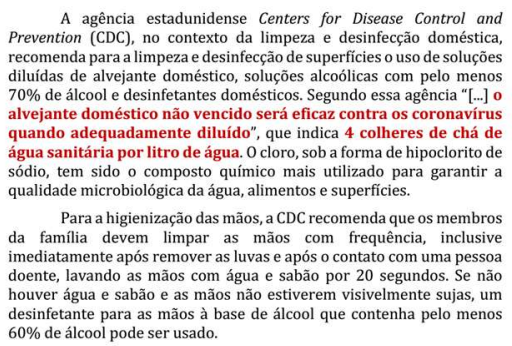

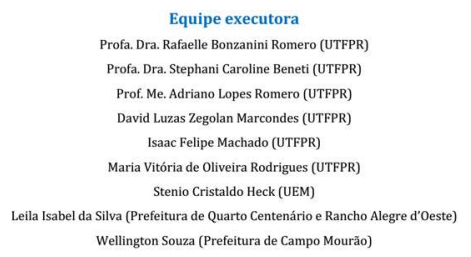

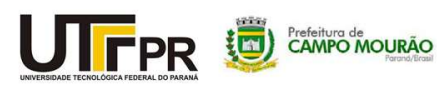
$\sim 4 \sim$

Fonte: Os autores.

A seção do folheto informativo indicada anteriormente tem como objetivo desmistificar a necessidade de uso de álcool em gel para a segura higienização das mãos. Observa-se que, ainda que a OMS indique a higienização das mãos com sabão e água corrente como principal forma de se proteger de doenças causadas por microrganismos, observamos que a população brasileira, assim como tem 
acontecido em outros países, têm intensificado a procura e aquisição de produtos à base de álcool etílico $70 \%$. Fato que tem resultado na falta desses produtos, para aquisição, em supermercados e farmácias. Quando encontrados, os preços dos produtos são, na maioria das vezes, superiores ao praticados antes do início da pandemia.

Vale ressaltar que o vírus que causa a COVID-19 persiste em superfícies inanimadas por até 9 dias, mas pode ser inativado eficientemente por procedimentos de desinfecção de superfícies. O uso de água sanitária e de sabão, por exemplo, são alternativas viáveis e mais acessíveis para a realização de desinfecção de superfícies. Os sabões produzidos em nosso grupo possuem pH básico e são indicados, como informado no rótulo dos produtos, para a higienização de roupas e de superfícies, eventualmente podem ser utilizados para higienização das mãos.

\section{CONSIDERAÇÕES FINAIS}

O projeto ora relatado teve boa aceitação por parte da administração dos quatro municípios parceiros, que têm engajado servidores das secretarias municipais de Saúde, da Ação Social, e do Meio Ambiente para contribuir com a execução do projeto. A população dessas cidades tem contribuído com arrecadação de óleo usado em fritura, e de embalagens para envase de produtos saneantes líquidos, contribuindo com a diminuição dos custos de produção e ampliação do quantitativo de produtos fabricados. Vale ressaltar que, quando o óleo usado em fritura é descartado de forma inadequada no meio ambiente "[...] provoca danos diversos aos ecossistemas aquáticos, além de provocar impermeabilização do solo e obstrução das galerias de esgoto ocasionando enchentes que geram transtornos que atingem toda a sociedade" (NEZI; UHDRE; ROMERO, 2011, p. 1).

Para além desse período de pandemia, o projeto prevê a implantação de uma planta piloto para fabricação de produtos saneantes domissanitários em um espaço cedido pela prefeitura de Campo Mourão, que contribuirá para a oferta de cursos de qualificação e geração de renda para pessoas em situação de vulnerabilidade social. Além disso, os produtos fabricados na planta piloto poderão ser utilizados em prédios públicos tais como escolas, secretarias, e postos de saúde. 


\title{
New pandemic, old ways of prevention: manufacturing and donation of sanitizing products for families in situations of social vulnerability
}

\begin{abstract}
The usage of household sanitizing products is an effective way to prevent disease-causing agents dissemination, such as the coronavirus responsible for the so called COVID-19 pandemic. Generally, pandemics can cause health problems to the population as a whole but are particularly harmful to members in social vulnerability groups. In this context, a group formed by professors and grad students from UTFPR - Campo Mourão, have been manufacturing and donating household sanitizing products to social vulnerability group families from Campo Mourão, Quarto Centenário, Rancho Alegre d'Oeste and Roncador counties. Among the manufactured and donated sanitizing products, one can highlight in terms of quantity, bar and liquid soaps produced from used cooking oil, donated by residents of the mentioned counties. So far, about 600 bar soap kits and 2000 liters of liquid soap have been donated, as well as pandemic information leaflets.
\end{abstract}

KEYWORDS: University extension. Sanitizing agents. Soap. COVID-19. 


\section{REFERÊNCIAS}

ANVISA. Resolução-RDC n. 42, de 25 de outubro de 2010.

CENTERS FOR DISEASE CONTROL AND PREVENTION (CDC). Guideline for Hand Hygiene in Health-Care Settings: Recommendations of the Healthcare Infection Control Practices Advisory Committee and the HICPAC/SHEA/APIC/IDSA Hand Hygiene Task Force. Morbidity and Mortality Weekly Report, v. 51, n. RR16, p. 144, 2002.

FERNANDES, P. A.; RAMOS M. J. O sabão contra a COVID-19. Revista Ciência Elementar, v. 8, n. 2, p. 019, 2020.

NEZI, S. M.; UHDRE, D. F.; ROMERO, A. L. Implementação do Projeto "reciclagem de óleos e gorduras usados em frituras através da fabricação de sabão" Na UTFPR. In: Encontro de Produção de Científica e Tecnologia, 6., 2011, Campo Mourão. Anais... Campo Mourão, PR: Fecilcam, 2011. Disponível em: $<$ http://www.fecilcam.br/nupem/anais_vi_epct/PDF/engenharias/01.pdf>. Acesso em: 01 maio 2020.

SOHRABI, C.; ALSAFI, Z.; O'NEILL, N.; KHAN, M.; KERWAN, A.; AL-JABIR, A.; IOSIFIDIS, C.; AGHA, R. World Health Organization declares global emergency: A review of the 2019 novel coronavirus (COVID-19). International Journal of Surgery, v. 76, p. 71-76, 2020.

WISNIAK, J. Soap - From beginning to understanding. Indian Journal of Chemical Technology, v. 11, p. 140-148, 2004.

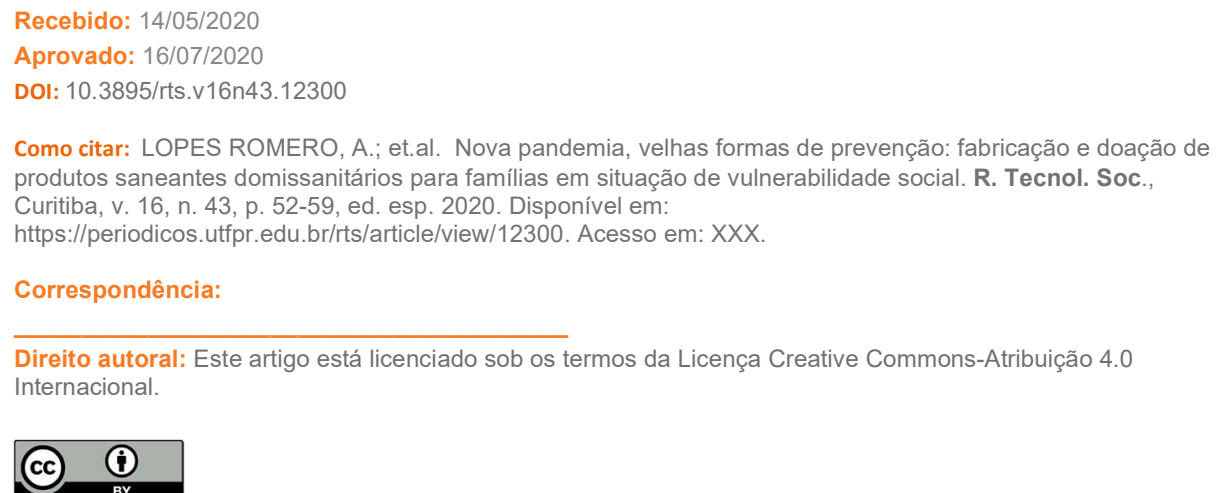

